\title{
Risk factors for acute kidney injury after surgery of the thoracic aorta using antegrade selective cerebral perfusion and moderate hypothermia
}

Davide Pacini, MD, ${ }^{\mathrm{a}}$ Antonio Pantaleo, MD, ${ }^{\mathrm{a}}$ Luca Di Marco, MD, ${ }^{\mathrm{a}}$ Alessandro Leone, MD, ${ }^{\mathrm{a}}$ Giuseppe Barberio, MD, ${ }^{\mathrm{a}}$ Alessandro Parolari, MD, ${ }^{\mathrm{b}}$ Giuliano Jafrancesco, $\mathrm{MD},{ }^{\mathrm{a}}$ and

Roberto Di Bartolomeo, $\mathrm{MD}^{\mathrm{a}}$

\begin{abstract}
Background: The development of acute kidney injury (AKI) in cardiac surgery is associated with increased morbidity and mortality. The aim of the study was to assess the incidence and risk factors for AKI after thoracic aorta surgery, using antegrade selective cerebral perfusion (ASCP) and moderate hypothermia.

Methods: We reviewed 641 patients undergoing thoracic aortic surgery, using ASCP and moderate hypothermia, from November 1996 to December 2012. Patient preoperative, intraoperative, and postoperative variables were evaluated for association with AKI with logistic regression analysis. Models including all variables and models, after the sequential removal of postoperative, and both postoperative and intraoperative variables, were assessed using receiver operating characteristic analysis.
\end{abstract}

Results: The mean age of the patients was 62.9 years, and 194 patients $(30 \%)$ were women. The overall incidence of AKI was $19.0 \%$. In-hospital mortality was significantly higher in the AKI group $(33.6 \%$ vs $6.7 \% ; P<.001)$. Logistic regression analysis identified 8 predictors of AKI: 4 of them were preoperative (priority, diabetes, preoperative glomerular filtration rate, and weight); 2 intraoperative (mitral valve and aortic valve replacement); and 2 postoperative (overall neurologic complication and reoperation for bleeding). Model-discrimination performance improved from an area under the curve (AUC) of 0.737 , for the model including only preoperative variables, to an AUC of 0.798 for the model including all variables $(P=.012)$.

Conclusions: The incidence of AKI after thoracic aorta surgery is fairly common, and its occurrence strongly affects outcomes. Preoperative renal status and preoperative conditions are the main influences on AKI development. Predictive models can be improved by adding intraoperative and postoperative variables. ( $\mathrm{J}$ Thorac Cardiovasc Surg 2015;150:127-33)

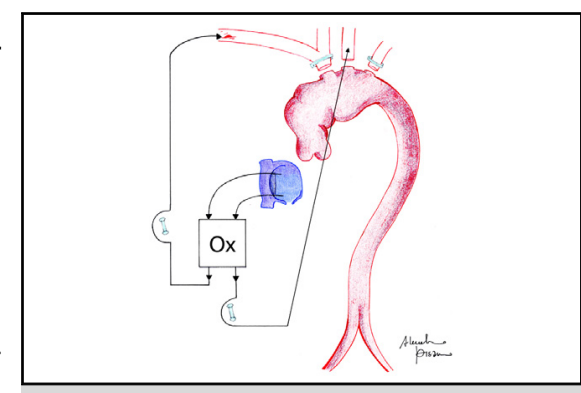

Schematic drawing of the cardiopulmonary bypass and antegrade selective cerebral perfusion circuit.

Central Message

Incidence of AKI after thoracic aortic surgery is fairly common, and strongly affects outcomes. Predictive models can be improved by adding intraoperative and postoperative variables.

\section{Perspective}

Thoracic aortic surgery is associated with greater risk of postoperative AKI. Incidence and risk factors in such surgery have not been widely investigated. In our series, 641 patients underwent aortic surgery using moderate hypothermia and ASCP. Overall AKI incidence was $19.0 \%$. Eight AKI predictors were identified: 4 preoperative, 2 intraoperative, and 2 postoperative. Predictive models can be improved, including preoperative, intraoperative, and postoperative variables.

See Editorial Commentary page 134.

\footnotetext{
From the a Department of Cardiac Surgery, S.Orsola-Malpighi Hospital, University of Bologna, Bologna; and ${ }^{\mathrm{b}}$ Department of Cardiac Surgery, Operative Unit of Cardiac Surgery and Translational Research, Istituto di Ricovero e Cura a Carattere Scientifico Policlinico San Donato-San Donato Milanese, Milan, Italy.

Read at The American Association for Thoracic Surgery Aortic Symposium, New York, New York, April 24-25, 2014.

Received for publication Nov 28, 2014; revisions received March 16, 2015; accepted for publication April 2, 2015; available ahead of print May 16, 2015.

Address for reprints: Davide Pacini, MD, Cardiac Surgery Dept, S.Orsola-Malpighi

Hospital, University of Bologna, 40128 Bologna, Italy (E-mail: dav.pacini@ gmail.com).

$0022-5223 / \$ 36.00$

Copyright (c) 2015 by The American Association for Thoracic Surgery

http://dx.doi.org/10.1016/j.jtcvs.2015.04.008
}

丹 Supplemental material is available online.

The incidence of acute kidney injury (AKI) after adult cardiac surgery ranges from $1 \%$ to $30 \%$, depending on the strictness of the definition, and increases perioperative morbidity, mortality, and costs. ${ }^{1,2}$ Because of the extent of the range of definitions for AKI, a consensus set of criteria for AKI was developed and given the acronym 


$$
\begin{aligned}
& \text { Abbreviations and Acronyms } \\
& \begin{aligned}
\text { AKI } & =\text { acute kidney injury } \\
\text { ASCP } & =\text { antegrade selective cerebral perfusion } \\
\text { AUC } & =\text { area under the curve } \\
\text { CI } & =\text { confidence interval } \\
\text { CPB } & =\text { cardiopulmonary bypass } \\
\text { RIFLE }= & \text { risk, injury, failure, loss of kidney } \\
& \text { function, and end-stage renal failure } \\
\text { ROC } & =\text { receiver operating characteristic }
\end{aligned}
\end{aligned}
$$

RIFLE (risk, injury, failure, loss of kidney function, and end-stage renal failure), enabling comparison between the various studies. ${ }^{3}$ Pre-existing renal dysfunction, diabetes, ventricular dysfunction, older age, hypertension, and prolonged cardiopulmonary bypass (CPB) time are well known risk factors for AKI that have been extensively evaluated in previous studies. ${ }^{4-9}$

However, AKI after surgery of the thoracic aorta has been less studied, and this kind of surgery is itself a risk factor for AKI, because of the complexity of the procedures, including circulatory arrest. In fact, studies ${ }^{10-13}$ have reported an incidence of any RIFLE category of between $29 \%$ and $50 \%$, with need of renal replacement therapy at $8 \%$ to $11 \%$. The aim of the current study was to: (1) investigate the incidence and risk factors for AKI after thoracic aorta surgery, using moderate hypothermia antegrade selective cerebral perfusion (ASCP); and (2) build a statistical model that can be used to improve our ability to predict AKI.

\section{METHODS}

We reviewed the data of 641 consecutive patients who underwent surgery of the thoracic aorta, using ASCP and moderate hypothermia, between November 2006 and December 2012, who did not require renal replacement therapy at the time of surgery. The primary outcome was postoperative AKI, defined by a $\geq 100 \%$ serum creatinine rise from baseline, or the need of temporary or permanent dialysis. Creatinine was assessed before surgery, daily for the first 3 postoperative days, and then every other day until discharge of the patient, unless clinical needs dictated morefrequent assessments. The preoperative glomerular filtration rate was estimated using Cockcroft and Gault's formula.

\section{Antegrade Selective Cerebral Perfusion and Operative Details}

Our method of ASCP and the technique of aortic replacement have been previously described. ${ }^{14}$ They can be summarized as follows: Arterial inflow was through the right axillary artery or innominate artery, ascending aorta, or femoral artery; venous drainage was by a single 2-stage cannula introduced into the right atrium, or in a few cases, the femoral vein. Pressure monitoring was achieved by means of the right and left radial artery pressure line. Nasopharyngeal, bladder, and skin temperatures were measured. Patient cooling avoided any gradient $>3^{\circ} \mathrm{C}$ between nasopharyngeal and bladder temperatures. Cerebral perfusion was initiated at a flow rate of 10 to $15 \mathrm{~mL} / \mathrm{Kg} /$ minute and adjusted to maintain the right radial arterial pressure between 40 and $70 \mathrm{~mm} \mathrm{Hg}$. The temperature of the cerebral perfusate was $1^{\circ} \mathrm{C}$ to $2^{\circ} \mathrm{C}$ less than the core temperature $\left(24^{\circ} \mathrm{C}-25^{\circ} \mathrm{C}\right)$.
In the case of right axillary artery or innominate artery cannulation, only the left common carotid artery was cannulated, and cerebral perfusion was obtained using the systemic pump at a flow rate of 8 to $10 \mathrm{~mL} / \mathrm{Kg} /$ minute and a separate roller pump at a flow rate of $5 \mathrm{~mL} / \mathrm{Kg} /$ minute. The innominate artery and the left subclavian artery were occluded at the time of ASCP. Blood gas management was performed according to the alpha-stat method.

\section{Statistical Analysis}

A retrospective analysis of our prospective computerized database collecting preoperative, perioperative, intraoperative, and postoperative variables (Appendix E1) was performed. The S.Orsola-Malpighi Hospital Institutional Review Board approved the use of this database for research without informed consent, on the condition that the subjects' identities were not revealed.

Continuous data are presented as mean \pm SD and compared with ANOVA or Mann-Whitney $U$ test results when indicated. Categoric variables are described using absolute frequencies and relative frequency rates, and compared using $\chi^{2}$ analysis or Fisher's exact test when indicated. Multivariable forward stepwise logistic regression analysis was used to determine independent predictors of AKI. ${ }^{15}$

Separate models were developed to assess the role of the different timing and categorization of the following variables on the primary outcome: preoperative, preoperative plus intraoperative, and preoperative plus intraoperative plus postoperative (Table 1); in the case of postoperative events and complications, events that were included in the analysis had to occur before AKI diagnosis. Preoperative, intraoperative, and postoperative variables that were assessed in the various models are reported in Appendix E1.

The levels of significance for a covariate acceptance in or removal from the model were set at 0.05 and 0.1 , respectively. Every multivariable model was tested for reliability with the Hosmer-Lemeshow statistic. ${ }^{16}$ In addition, the multivariate odds ratio with its $95 \%$ confidence interval (CI) for each independent variable in the final regression models was computed. Data analysis was performed using SPSS 19.0 software for Windows (SPSS, Inc, Chicago, Ill).

Finally, the discriminatory ability of every logistic regression model developed was tested using the area under the receiver operating characteristic (ROC) curve, based on the nonparametric method of DeLong and colleagues, ${ }^{17}$ as implemented with MedCalc software, version 11.4.4 (MedCalc Software, Mariakerke, Belgium); Bonferroni's correction for multiple comparison was applied when required. The ROC evaluation was done independently from the regression analysis; ie, the predictive models were not selected to maximize the area under the curve (AUC).

\section{RESULTS}

The overall incidence of AKI was 19.0\% (122 patients); renal replacement therapy was required in 59 patients $(9.2 \%)$; it was temporary in $36(5.6 \%)$, and permanent in $23(3.6 \%)$. In-hospital mortality was significantly higher in the AKI group (41 of $122 ; 33.6 \%$ vs 35 of $519 ; 6.7 \%$; $P<.001)$. Patients who required renal replacement therapy had a mortality rate of $45.8 \%$; it was $60.9 \%$ (14 of 23 ) in patients in whom the dialysis was permanent, and $36.1 \%$ (13 of $36)$ in patients in whom dialysis was temporary $(P=.063)$.

\section{Univariate Analysis}

Patients who developed AKI were older, had higher serum creatinine levels, and a lower glomerular filtration rate at baseline. They more frequently had urgent or emergency surgery, and presentation with type A dissection; and they 
TABLE 1. Variables included in the logistic regression analysis models

\section{Logistic}

regression model $\quad$ Preoperative Intraoperative Postoperative

\begin{tabular}{llll}
\hline 3 categories & Yes & Yes & Yes \\
2 categories & Yes & Yes & No \\
1 category & Yes & No & No \\
\hline
\end{tabular}

had less frequent chronic aneurysm. They had an increased incidence of hypertension and diabetes (Table 2). Concerning intraoperative features (Table 3), patients who developed AKI did not differ in terms of extension of aortic replacement, compared with patients who did not develop this complication. However, need to replace either the mitral or aortic valve were both more frequent in patients who developed AKI, whereas patients who did not were treated more frequently with a modified Bentall procedure. Finally, perfusion and crossclamp times, as well as visceral ischemia and selective cerebral perfusion times did not differ between groups. The analysis of postoperative complications showed that patients developing AKI had higher incidences of both permanent and transitory neurologic deficit, stroke, spinal cord injury, and pulmonary and cardiac complications (Table 4). Moreover, they more frequently underwent reoperation for bleeding, and had an increased need of prolonged inotropic support.

\section{Multivariate Analysis: Independent Predictors of Acute Kidney Injury}

Table 5 reports the results of logistic regression analysis models for AKI based on different variable categories (preoperative, intraoperative, and postoperative management) included in each analysis. The model called " 3 categories"- simultaneously assessing all the variables collected-showed that 8 variables are significantly associated with AKI. Of these, 4 are preoperative, 2 are associated with operative details, and 2 pertain to postoperative complications. All the tested models showed that surgical priority, preoperative glomerular filtration rate, and preoperative weight are significantly associated with AKI. This result was confirmed by the models developed after the sequential removal of postoperative and intraoperative management variables. Moreover, the type of surgery additionally affects the occurrence of the outcome of interest, as well as some postoperative complications, such as bleeding and neurologic problems.

Receiver operating characteristic analysis (Table 6 and Figure 1) shows that the models developed had significantly different discriminatory powers, and that adding intraoperative variables to only the preoperative variables did not improve discrimination of the predictive model. On the other hand, adding postoperative variables significantly improved model discrimination, from an AUC of 0.737 (95\% CI: 0.698-0.773) for the model including only preoperative variables, to an AUC of 0.798 (95\% CI: 0.7620.831 ) for the model including all the variable categories.

\section{DISCUSSION}

Open surgery still represents the gold standard in the treatment of acute and chronic disease of the ascending aorta and aortic arch. Although substantial improvements

TABLE 2. Preoperative variables

\begin{tabular}{|c|c|c|c|c|}
\hline Variables & Overall $(n=641)$ & No AKI $(n=519)$ & AKI $(\mathbf{n}=122)$ & $P$ value \\
\hline Age (y) & $62.9 \pm 12.1$ & $62.3 \pm 12.6$ & $65.6 \pm 9.5$ & .015 \\
\hline Height $(\mathrm{cm})$ & $170 \pm 9.2$ & $170 \pm 9.3$ & $169 \pm 8.6$ & .41 \\
\hline Weight $(\mathrm{kg})$ & $77.5 \pm 13.9$ & $77.1 \pm 13.2$ & $79.0 \pm 16.5$ & .16 \\
\hline Gender, male & $447(69.7)$ & $361(69.6)$ & $86(70.5)$ & .84 \\
\hline Serum creatinine $(\mathrm{mg} / \mathrm{dL})$ & $1.17 \pm 0.51$ & $1.11 \pm 0.47$ & $1.40 \pm 0.61$ & $<.001$ \\
\hline Glomerular filtration rate $\left(\mathrm{mL} / \mathrm{min} / 1.73 \mathrm{~m}^{2}\right)$ & $71 \pm 28.0$ & $74 \pm 27.7$ & $58 \pm 25.3$ & $<.001$ \\
\hline Logistic euroSCORE & $9.3 \pm 2.8$ & $9.2 \pm 2.8$ & $9.6 \pm 2.8$ & .239 \\
\hline Ejection fraction $(\%)$ & $57.2 \pm 2$ & $57.5 \pm 7.7$ & $56.2 \pm 9.1$ & .136 \\
\hline Urgent and/or emergency & $239(37.3)$ & $174(33.5)$ & $65(53.3)$ & $<.001$ \\
\hline Chronic aneurysm & $297(46.3)$ & $252(48.6)$ & $45(36.9)$ & .020 \\
\hline Type A dissection & $266(41.5)$ & $200(38.5)$ & $66(54.1)$ & .002 \\
\hline Intramural hematoma & $23(3.6)$ & $16(3.1)$ & $7(5.7)$ & .17 \\
\hline Penetrating aortic ulcer & $9(1.4)$ & $9(1.7)$ & 0 & .22 \\
\hline Type B dissection & $33(5.1)$ & $26(5)$ & $7(5.7)$ & .74 \\
\hline Hypertension & $430(67.1)$ & $337(64.9)$ & $93(76.2)$ & .017 \\
\hline Coronary artery disease & $87(13.6)$ & $71(13.7)$ & $16(13.1)$ & .870 \\
\hline Chronic obstructive pulmonary disease & $24(3.7)$ & $20(3.9)$ & $4(3.3)$ & $>.99$ \\
\hline Cerebrovascular accident & $44(6.9)$ & $36(6.9)$ & $8(6.6)$ & .882 \\
\hline Diabetes & $30(4.7)$ & $19(3.7)$ & $11(9.0)$ & .012 \\
\hline Smoking & $201(31.4)$ & $166(32.0)$ & 35 (28.7) & .48 \\
\hline Redo & $165(25.7)$ & $141(27.2)$ & $24(19.7)$ & .088 \\
\hline
\end{tabular}

Values are $\mathrm{n}(\%)$ or mean $\pm \mathrm{SD}$, unless otherwise indicated. AKI, Acute kidney injury; euroSCORE, European System for Cardiac Operative Risk Evaluation. 
TABLE 3. Operative variables

\begin{tabular}{|c|c|c|c|c|}
\hline Variables & Overall $(n=641)$ & No AKI $(n=519)$ & AKI $(n=122)$ & $P$ value \\
\hline \multicolumn{5}{|l|}{ Extent of aortic replacement } \\
\hline Ascending & 49 (7.6) & $37(7.1)$ & $12(9.8)$ & .457 \\
\hline Ascending and/or hemiarch & $235(36.7)$ & $191(36.8)$ & $44(36.1)$ & .995 \\
\hline Ascending + arch & $215(33.5)$ & $176(33.9)$ & $39(32.0)$ & .850 \\
\hline Arch & 113 (17.6) & $90(17.3)$ & $23(18.9)$ & .842 \\
\hline Arch + descending & $15(2.3)$ & $12(2.3)$ & $3(2.5)$ & .812 \\
\hline Ascending + arch + descending & $14(2.2)$ & $13(2.5)$ & $1(0.8)$ & .435 \\
\hline \multicolumn{5}{|l|}{ Associated procedures $(\%)$} \\
\hline Modified Bentall & $191(29.8)$ & $164(31.6)$ & $27(22.1)$ & .040 \\
\hline CABG & $46(7.2)$ & $33(6.4)$ & $13(10.7)$ & .18 \\
\hline Aortic valve replacement & $78(12.2)$ & $55(10.6)$ & $23(18.9)$ & .012 \\
\hline Elephant trunk & $53(8.3)$ & $45(8.7)$ & $8(6.6)$ & .45 \\
\hline Frozen elephant trunk & $110(17.2)$ & $85(16.4)$ & $25(20.5)$ & .28 \\
\hline Mitral valve repair & $5(0.8)$ & $5(1.0)$ & 0 & .35 \\
\hline Mitral valve replacement & $9(1.4)$ & $3(0.6)$ & $6(4.9)$ & .002 \\
\hline Aortic valve sparing & $35(5.5)$ & $27(5.2)$ & $8(6.6)$ & .55 \\
\hline \multicolumn{5}{|l|}{$\mathrm{CPB}$ and perfusion } \\
\hline Axillary artery cannulation & $207(32.3)$ & $164(31.6)$ & $43(35.2)$ & .44 \\
\hline CPB time (min) & $205 \pm 65$ & $203 \pm 66$ & $212 \pm 60$ & .16 \\
\hline Aortic crossclamp time (min) & $135 \pm 48$ & $135 \pm 49$ & $136 \pm 44$ & .79 \\
\hline ASCP time (min) & $63 \pm 33$ & $63 \pm 34$ & $64 \pm 30$ & .69 \\
\hline Visceral ischemia (min) & $54 \pm 26$ & $54 \pm 27$ & $56 \pm 22$ & .49 \\
\hline Nasopharyngeal temperature $\left({ }^{\circ} \mathrm{C}\right)$ & $24.5 \pm 2.0$ & $24.6 \pm 2.0$ & $24.4 \pm 1.9$ & .38 \\
\hline Bladder temperature $\left({ }^{\circ} \mathrm{C}\right)$ & $25.7 \pm 1.9$ & $25.7 \pm 1.9$ & $25.7 \pm 1.9$ & .85 \\
\hline
\end{tabular}

Values are $\mathrm{n}(\%)$, mean $\pm \mathrm{SD}$, unless otherwise indicated. $A K I$, Acute kidney injury; $C A B G$, coronary artery bypass grafting; $C P B$, cardiopulmonary bypass; $A S C P$, antegrade selective cerebral perfusion.

in surgical and anesthesiology techniques, and in the management of cerebral and visceral organ protection, have been made, this kind of surgery is still associated with a more than negligible level of mortality and morbidity. Many studies evaluating risk factors for mortality and neurologic deficits are available, but renal complications have not been exhaustively assessed yet. Moreover, most studies on AKI after thoracic aorta surgery were performed in patients undergoing deep hypothermic circulatory arrest. Very few studies have been conducted on patients treated with moderate hypothermia and ASCP, and in most of them, aortic dissection was the indication for surgery.

In the present paper, we evaluated our overall experience with moderate hypothermia and ASCP for the treatment of acute and chronic aortic disease, focusing on the incidence and risk factors for postoperative AKI. The incidence of postoperative AKI, based on our definition, which matches RIFLE criteria, ${ }^{3}$ was $19 \%$. It was significantly lower than that reported in previous studies on aortic arch surgery, ${ }^{10-13}$ in which the incidence of any RIFLE category ranged from $29 \%$ to $50 \%$.

This significant contrast may be partially explained by the difference in definition used for postoperative renal dysfunction. On the other hand, considering that patient characteristics and the types of interventions were similar to those in our study, the differences in the temperatures used during circulatory arrest may have played a role in the development of AKI. In most of these studies, patients

TABLE 4. Postoperative variables

\begin{tabular}{|c|c|c|c|c|}
\hline Variables & Overall $(n=641)$ & No AKI $(n=519)$ & $\operatorname{AKI}(n=122)$ & $P$ value \\
\hline Permanent neurologic deficit* & $59(9.2)$ & $30(5.8)$ & $29(23.8)$ & .000 \\
\hline Stroke & $46(7.2)$ & $23(4.4)$ & $23(18.9)$ & .000 \\
\hline Spinal cord injury & $16(2.5)$ & $9(1.7)$ & $7(5.7)$ & .019 \\
\hline Transient neurologic deficit & $69(10.8)$ & $48(9.2)$ & $21(17.2)$ & .011 \\
\hline Pulmonary complications & $139(21.7)$ & $73(14.1)$ & $66(54.1)$ & .000 \\
\hline Cardiac complications & $105(16.4)$ & $74(14.3)$ & $31(25.4)$ & .003 \\
\hline Prolonged inotropic support & $26(4.1)$ & $16(3.1)$ & $10(8.2)$ & .018 \\
\hline Acute myocardial infarction & $12(1.9)$ & $8(1.5)$ & $4(3.3)$ & .256 \\
\hline Reoperation for bleeding & $58(9.0)$ & $31(6.0)$ & $27(22.1)$ & .000 \\
\hline
\end{tabular}

$\overline{A K I}$, Acute kidney injury. *Three patients developed both stroke and spinal cord injury. 
TABLE 5. Analysis of risk factors for acute kidney injury based on the different groups of variables included in the model

\begin{tabular}{|c|c|c|c|c|}
\hline Type of variable & Variable & $P$ value & OR & $\mathbf{9 5} \% \mathbf{C I}$ \\
\hline \multicolumn{5}{|l|}{3 categories } \\
\hline \multirow[t]{4}{*}{ Preoperative } & Glomerular filtration rate $\left(\mathrm{mL} / \mathrm{min} / 1.73 \mathrm{~m}^{2}\right)$ & .000 & 0.971 & $0.960-0.982$ \\
\hline & Weight $(\mathrm{kg})$ & .001 & 1.033 & $1.013-1.053$ \\
\hline & Priority (urgent and emergency) & .009 & 1.92 & $1.18-3.16$ \\
\hline & Diabetes & .045 & 2.70 & $1.17-7.11$ \\
\hline \multirow[t]{2}{*}{ Intraoperative } & Mitral valve replacement & .000 & 17.6 & $4.0-77.0$ \\
\hline & Aortic valve replacement & .015 & 2.26 & $1.17-4.38$ \\
\hline \multirow[t]{2}{*}{ Postoperative } & Permanent neurologic complications & .000 & 4.99 & $2.47-10.1$ \\
\hline & Reoperation for bleeding & .000 & 3.59 & $1.79-7.18$ \\
\hline \multicolumn{5}{|c|}{ Hosmer-Lemeshow goodness-of-fit test: $\chi^{2}=11.720, P=.164$} \\
\hline \multicolumn{5}{|l|}{2 categories } \\
\hline \multirow[t]{4}{*}{ Preoperative } & GFR $\left(\mathrm{mL} / \mathrm{min} / 1.73 \mathrm{~m}^{2}\right)$ & .000 & 0.970 & $0.960-0.981$ \\
\hline & Weight $(\mathrm{kg})$ & .000 & 1.036 & $1.017-1.055$ \\
\hline & Priority (urgent and emergency) & .000 & 2.34 & $1.47-3.73$ \\
\hline & Diabetes & .053 & 2.54 & $0.99-6.50$ \\
\hline \multirow[t]{2}{*}{ Intraoperative } & Mitral valve replacement & .000 & 15.3 & $3.49-67.5$ \\
\hline & Aortic valve replacement & .014 & 2.18 & $1.17-4.08$ \\
\hline \multicolumn{5}{|c|}{ Hosmer-Lemeshow goodness-of-fit test: $\chi^{2}=9.388, P=.311$} \\
\hline \multicolumn{5}{|l|}{1 category } \\
\hline \multirow[t]{4}{*}{ Preoperative } & GFR $\left(\mathrm{mL} / \mathrm{min} / 1.73 \mathrm{~m}^{2}\right)$ & .000 & 0.970 & $0.960-0.981$ \\
\hline & Priority (urgent and emergency) & .001 & 2.19 & $1.39-3.47$ \\
\hline & Weight (kg) & .001 & 1.030 & $1.012-1.048$ \\
\hline & Hypertension & .051 & 2.54 & $0.99-2.89$ \\
\hline Hosmer-Lemes & of-fit test: $\chi^{2}=14.258, P=.075$ & & & \\
\hline
\end{tabular}

$O R$, Odds ratio; $C I$, confidence interval; GFR, glomerular filtration rate.

underwent aortic surgery with deep hypothermic circulatory arrest, and many of our patients had moderate hypothermia. In fact, deep hypothermic circulatory arrest has been demonstrated to be associated with endothelial dysfunction of the pulmonary veins and renal arteries, and this dysfunction may be associated with adult respiratory distress syndrome and renal failure. ${ }^{18}$ Other authors evaluated the systemic inflammatory response at various temperatures and noted that moderate hypothermia is associated with a reduced inflammatory response and consequently less organ injury. ${ }^{19-21}$

A similar incidence of postoperative AKI (17.7\%) has recently been reported in a series of 851 patients, by

TABLE 6. Analysis of discriminatory performance of the multivariate models, based on the various classes of variables

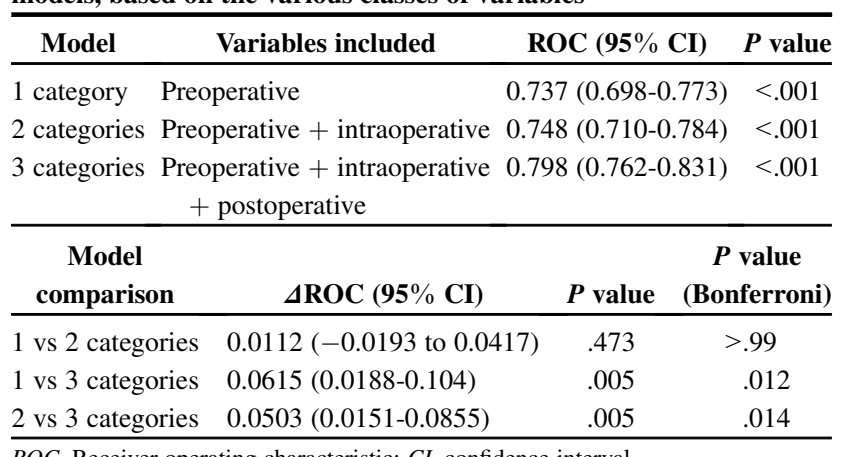

$R O C$, Receiver operating characteristic; $C I$, confidence interval.
Englberger and colleagues. ${ }^{22}$ However, they described a population undergoing elective surgery with only $28 \%$ of the patients that underwent circulatory arrest in deep hypothermia. Previous studies have shown that moderate hypothermia at $25^{\circ} \mathrm{C}$ to $26^{\circ} \mathrm{C}$ in addition to ASCP can provide

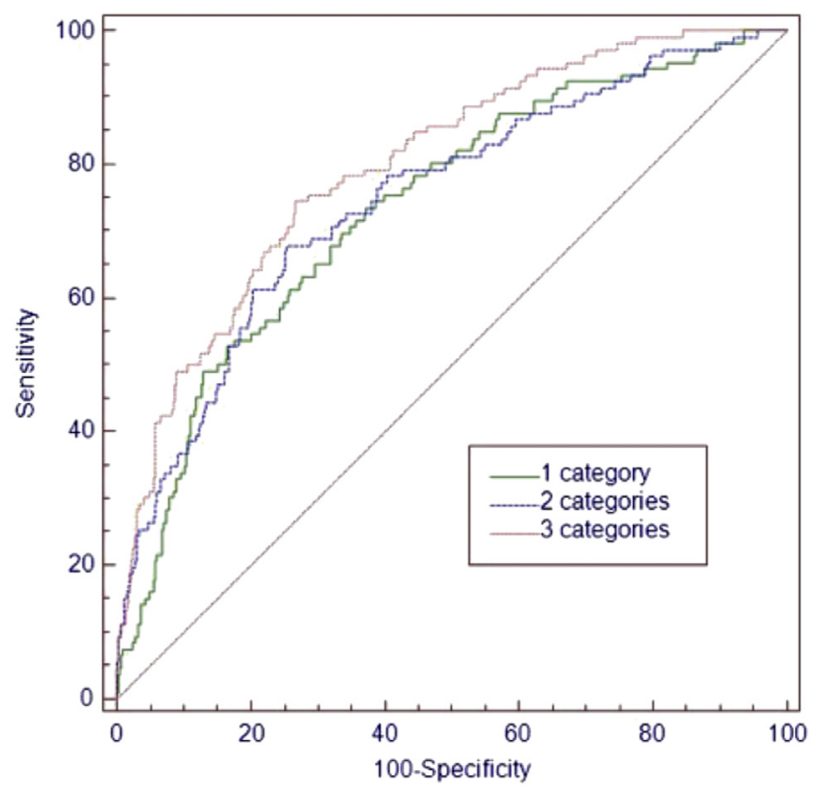

FIGURE 1. Receiver operating characteristic curves show the sensitivity of prediction of AKI versus 100-specificity for the 3 risk algorithms. The solid line represents the absence of discrimination. 
adequate protection of not only the central nervous system, but also the visceral organs when circulatory arrest times are $<60$ minutes. ${ }^{14,19,23}$ Moderate hypothermia can represent a valid compromise, by allowing good overall body protection and avoiding the well-known hypothermiarelated side effects.

However, because the incidence of AKI is multifactorial, further improvements will be achieved by additional strategies aimed at improving the patient profile. In other words, we may assume that a preoperative approach aimed at improving preoperative renal function and decreasing preoperative creatinine levels will improve the results of this surgery, in cases in which this approach is feasible (eg, with elective patients).

Once postoperative AKI has occurred, it negatively and prominently influences the outcomes. In our study, inhospital mortality in the AKI group was $33.6 \%$, compared with $6.7 \%$ in patients who did not experience AKI $(P<.001)$.

Multivariate analysis was performed to investigate predictor variables of postoperative AKI. Moreover, to increase precision of the analysis, as previously demonstrated ${ }^{24}$ we elaborated 3 models according to the included variables: Model predictions are more precise with addition of all the variables. In fact, ROC analysis showed a significant improvement in AUC, in the model where all the variable categories were included (preoperative, intraoperative, and postoperative). The addition of only the intraoperative to the preoperative variables, however, did not significantly increase precision of the model predictors.

The strongest independent risk factors for postoperative AKI were priority and preoperative glomerular filtration rate, both well known risk factors for postoperative AKI. ${ }^{10,13,25,26}$ As in other studies on cardiac surgery, we found that even hypertension and diabetes were important predictors of postoperative AKI: Both negatively affect renal function. ${ }^{27}$

Conversely, although CPB time has been shown to be an independent risk factor for AKI after cardiac surgery, ${ }^{24}$ and even after aortic surgery, ${ }^{22}$ our findings showed no association. Consistent with these results, we found that the Bentall procedure, which increases operative times, including $\mathrm{CPB}$ time but is usually performed in young patients in good general condition, was performed less frequently in patients with, versus without, AKI. On the other hand, mitral valve replacement and aortic valve replacement, which also prolong CPB time, were found to be independently associated with development of postoperative AKI. However, patients undergoing either mitral or aortic valve replacement usually have impaired cardiac function, which can promote postoperative low cardiac-output syndrome and development of AKI.

Our study has several limitations. First, it is a retrospective study, and for this reason, can establish an association, but not a causal link, between AKI and independent predictors. Inclusion of postoperative variables in our analysis is somehow questionable; it may be confounding, and determining the exact temporal relationship of some factors (neurologic and pulmonary complications, bleeding, etc.) with the dependent variable could be difficult. Moreover, the definition of renal dysfunction in this study was not based on the RIFLE criteria, owing to the unavailability of the urine output data.

In conclusion, the incidence of AKI after thoracic aorta surgery is fairly common, and its occurrence strongly affects the outcome. Preoperative renal function and preoperative patient conditions mainly influence AKI development. Predictive models can be sensibly improved by adding intraoperative and postoperative variables.

\section{Conflict of Interest Statement}

Authors have nothing to disclose with regard to commercial support.

\section{References}

1. Chertow GM, Lazarus JM, Christiansen CL, Cook EF, Hammermeister KE, Grover F, et al. Preoperative renal risk stratification. Circulation. 1997;95: 878-84.

2. Lin CL, Pan KY, Hsu PY, Yang HY, Guo HL, Huang CC. Preoperative 24-hour urine amount as an independent predictor of renal outcome in poor cardiac function patients after coronary artery bypass grafting. J Crit Care. 2004;19: 92-8.

3. Bellomo R, Ronco C, Kellum JA, Mehta RL, Palevsky P, Acute Dialysis Quality Initiative workgroup. Acute renal failure-definition, outcome measures, animal models, fluid therapy and information technology needs: The Second International Consensus Conference of the Acute Dialysis Quality Initiative (ADQI) Group. Crit Care. 2004;8:R204-12.

4. Heise D, Sundermann D, Braeuer A, Quintel M. Validation of a clinical score to determine the risk of acute renal failure after cardiac surgery. Eur J Cardiothorac Surg. 2010;37:710-6.

5. Brown JR, Cochran RP, Leavitt BJ, Dacey LJ, Ross CS, MacKenzie TA, et al. Multivariable prediction of renal insufficiency developing after cardiac surgery. Circulation. 2007;116(11 Suppl):I139-43.

6. Fortescue EB, Bates DW, Chertow GM. Predicting acute renal failure after coronary bypass surgery: cross-validation of two risk-stratification algorithms. Kidney Int. 2000;57:2594-602.

7. Thakar CV, Arrigain S, Worley S, Yared JP, Paganini EP. A clinical score to predict acute renal failure after cardiac surgery. J Am Soc Nephrol. 2005;16: $162-8$.

8. Noyez L. Influence of the definition of acute renal failure post-cardiac surgery on incidence, patient identification, and identification of risk factors. Eur J Cardiothorac Surg. 2011;39:e8-12.

9. Palomba H, de Castro I, Neto AL, Lage S, Yu L. Acute kidney injury prediction following elective cardiac surgery: AKICS score. Kidney Int. 2007;72:624-31.

10. Arnaoutakis GJ, Bihorac A, Martin TD, Hess PJ Jr, Klodell CT, Ejaz AA, et al. RIFLE criteria for acute kidney injury in aortic arch surgery. $J$ Thorac Cardiovasc Surg. 2007;134:1554-60.

11. Hobson CE, Yavas S, Segal MS, Schold JD, Tribble CG, Layon AJ, et al. Acute kidney injury is associated with increased long-term mortality after cardiothoracic surgery. Circulation. 2009;119:2444-53.

12. Kim WH, Lee SM, Choi JW, Kim EH, Lee JH, Jung JW, et al. Simplified clinical risk score to predict acute kidney injury after aortic surgery. J Cardiothorac Vasc Anesth. 2013;27:1158-66.

13. Augoustides JG, Pochettino A, Ochroch EA, Cowie D, Weiner J, Gambone AJ, et al. Renal dysfunction after thoracic aortic surgery requiring deep hypothermic circulatory arrest: definition, incidence, and clinical predictors. J Cardiothorac Vasc Anesth. 2006;20:673-7. 
14. Pacini D, Leone A, Di Marco L, Marsilli D, Sobaih F, Turci S, et al. Antegrade selective cerebral perfusion in thoracic aorta surgery: safety of moderate hypothermia. Eur J Cardiothorac Surg. 2007;31:618-22.

15. Bell M, Liljestam E, Granath F, Fryckstedt J, Ekbom A, Martling CR. Optimal follow-up time after continuous renal replacement therapy in actual renal failure patients stratified with the RIFLE criteria. Nephrol Dial Transplant. 2005;20: 354-60.

16. Lemeshow S, Hosmer DW Jr. A review of goodness of fit statistics for use in the development of logistic regression models. Am J Epidemiol. 1982;115:92-106.

17. DeLong ER, DeLong DM, Clarke-Pearson DL. Comparing the areas under two or more correlated receiver operating characteristic curves: a nonparametric approach. Biometrics. 1988;44:837-45.

18. Cooper WA, Duarte IG, Thourani VH, Nakamura M, Wang NP, Brown WM III, et al. Hypothermic circulatory arrest causes multisystem vascular endothelial dysfunction and apoptosis. Ann Thorac Surg. 2000;69:696-702.

19. Pacini D, Pantaleo A, Di Marco L, Leone A, Barberio G, Murana G, et al. Visceral organ protection in aortic arch surgery: safety of moderate hypothermia. Eur J Cardiothorac Surg. 2014;46:438-43.

20. Qing M, Vazquez-Jimenez JF, Klosterhalfen B, Sigler M, Schumacher K, Duchateau J, et al. Influence of temperature during cardiopulmonary bypass on leukocyte activation, cytokine balance, and post-operative organ damage. Shock. 2001;15:372-7

21. Kamija H, Hagl C, Kropivnitskaya I, Bothing D, Kallenbach K, Khaladj N, et al. The safety of moderate hypothermic lower body circulatory arrest with selective cerebral perfusion: a propensity score analysis. J Thorac Cardiovasc Surg. 2007; 133:501-9.
22. Englberger L, Suri RM, Greason KL, Burkhart HM, Sundt TM III, Daly RC, et al Deep hypothermic circulatory arrest is not a risk factor for acute kidney injury in thoracic aortic surgery. J Thorac Cardiovasc Surg. 2011;141:552-8.

23. Pacini D, Di Marco L, Leone A, Di Bartolomeo R, Sodeck G, Englberger L, et al. Antegrade selective cerebral perfusion and moderate hypothermia in aortic arch surgery: clinical outcomes in elderly patients. Eur J Cardiothorac Surg. 2012;42: 249-53.

24. Parolari A, Pesce LL, Pacini D, Mazzanti V, Salis S, Sciacovelli C, et al. Risk factors for perioperative acute kidney injury after adult cardiac surgery: role of perioperative management. Ann Thorac Surg. 2012;93:584-91.

25. Geirsson A, Szeto WY, Pochettino A, McGarvey ML, Keane M, Woo YJ, et al Significance of malperfusion syndromes prior to contemporary surgical repair for acute type A dissection: outcomes and need for additional revascularizations. Eur J Cardiothorac Surg. 2007;32:255-62.

26. Roh GU, Lee JW, Nam SB, Lee J, Choi JR, Shim YH. Incidence and risk factor of acute kidney injury after thoracic aortic surgery for acute dissection. Ann Thorac Surg. 2012:94:766-71.

27. Aronson S, Fontes ML, Miao Y, Mangano DT. Risk index for perioperative rena dysfunction/failure: critical dependence on pulse pressure hypertension. Circulation. 2007;115:733-42.

Key Words: acute kidney injury, thoracic aorta surgery, cerebral protection, logistic regression analysis, ROC analysis

Readers who found these articles interesting may also like to read the following papers found in recent and future issues of our sister publications, Seminars in Thoracic and Cardiovascular Surgery and Operative Techniques in Thoracic and Cardiovascular Surgery!

\section{Acquired Cardiovascular Disease: Aortic Disease}

State of the Art: Thoralf Sundt. Current Understandings and Approach to the Management of Aortic Intramural Hematomas. Semin Thorac Cardiovasc Surg. Summer 2014;26(2):123-131. 
APPENDIX E1. PREOPERATIVE, INTRAOPERATIVE, AND POSTOPERATIVE VARIABLES

Preoperative variables

1. Age (y)

2. Height $(\mathrm{cm})$

3. Weight $(\mathrm{kg})$

4. Gender, male

5. Serum creatinine $(\mathrm{mg} / \mathrm{dL})$

6. Glomerular filtration rate $(\mathrm{mL} / \mathrm{min})$

7. Logistic euroSCORE

8. Urgent and/or emergency

9. Chronic aneurysm

10. Type A dissection

11. Intramural hematoma

12. Penetrating aortic ulcer

13. Type B dissection

14. Hypertension

15. Coronary artery disease

16. Chronic obstructive pulmonary disease

17. Cerebrovascular accident

18. Diabetes

19. Smoking

20. Redo

Operative variables

Extent of aortic replacement

21. Ascending + aortic arch

22. Ascending aorta and/or hemiarch

23. Aortic arch

24. Aortic arch + descending aorta

25. Ascending

Associated procedures ( $\%)$

26. Modified Bentall

27. Coronary artery bypass grafting

28. Aortic valve replacement

29. Elephant trunk

30. Frozen elephant trunk

31. Mitral valve repair

32. Mitral valve replacement

33. Aortic valve sparing

CPB and perfusion

34. Axillary artery cannulation

35. CPB time ( $\mathrm{min})$

36. Aortic crossclamp time (min)

37. ASCP time (min)

38. Visceral ischemia ( $\mathrm{min})$

39. Nasopharyngeal temperature $\left({ }^{\circ} \mathrm{C}\right)$

40. Bladder temperature $\left({ }^{\circ} \mathrm{C}\right)$

\section{Continued}

Postoperative variables

41. Permanent neurologic deficit

42. Stroke

43. Spinal cord injury

44. Transient neurologic deficit

45. Pulmonary complications

46. Cardiac complications

47. Prolonged inotropic support

48. Acute myocardial infarction

49. Reoperation for bleeding

EuroSCORE, European System for Cardiac Operative Risk Evaluation; $C P B$, cardiopulmonary bypass; $A S C P$, antegrade selective cerebral perfusion. 